CLINICAL ETHICS

\title{
What makes a good GP? An empirical perspective on virtue in general practice
}

\author{
A Braunack-Mayer
}

$J$ Med Ethics 2005;31:82-87. doi: 10.1136/jme.2003.003996

This paper takes a virtuist approach to medical ethics to explore, from an empirical angle, ideas about settled ways of living a good life. Qualitative research methods were used to analyse the ways in which a group of 15 general practitioners (GPs) articulated notions of good doctoring and the virtues in their work. I argue that the GPs, whose talk is analysed here, defined good general practice in terms of the ideals of accessibility, comprehensiveness, and continuity. They regarded these ideals significant both for the way they dealt with morally problematic situations and for how they conducted their professional lives more generally. In addition, I argue that the GPs who articulated these ideals most clearly were able to, in part, because they shared the experience of working in rural areas. This experience helped them to develop an understanding of the nature of general practice that their urban colleagues were less able to draw on. In that sense, the structural and organisational framework of general practice in rural areas provided the context for their understanding of ideals in general practice.

\section{Correspondence to: A Braunack-Mayer, Lecturer in Ethics, Department of Public Health, University of Adelaide, SA 5005, Australia; annette. braunackmayer@ adelaide.edu.au}

Received 16 March 2003 In revised form 25 November 2003 Accepted for publication 5 February 2004 practitioners (GPs) articulated notions of good doctoring and the virtues in their work.

\section{METHODS}

The empirical work reported in this paper is drawn from a qualitative study of how GPs make decisions about moral problems. During 1993, I conducted semistructured interviews with 15 GPs recruited through the South Australian branch of the Royal Australian College of General Practitioners (RACGP). The GPs who volunteered were a self-selected group in active general practice and, for a wide variety of reasons, were interested in ethics. Table 1 provides brief biographical information about each GP. ${ }^{12}$

Clearly, this sampling method had implications for the research and findings reported in this paper. The GPs I interviewed all shared the ability to conceive of their work in a way that included the notion of a moral domain. They were probably more sensitive to moral issues and perhaps more adept at moral deliberation than the mythical average GP. These factors suggest that, to some extent, I was working with "moral experts". However, I had no real way of knowing whether this was the case. They might not have been more reflective about moral issues but just more articulate or communicative.

As my research proceeded, evidence both for and against the "moral experts" label mounted. At the same time, I was also working on a number of other projects with and concerning GPs. ${ }^{14-18}$ In that work, I was repeatedly struck by how diffident GPs were about my research. I learnt that, with most GPs, talking about ethics in general practice was a surefire way to kill the conversation. The GPs interviewed for this study clearly did not respond that way, so perhaps the "moral expert" label had some currency.

Against this view, I had contrary evidence by way of the responses offered by the GPs at the end of the interview when I asked why they had decided to become involved in the study. The breadth of responses-from being troubled about an issue, to wanting an opportunity to chat, to having a longstanding interest in "doctor-doctor ethics", to no reason in particular-suggested that many things besides an interest in the moral realm or formal bioethics prompted their interest. In addition, I had been an undergraduate medical student in the same year as two of the GPs I interviewed, and I had the sense that those two were motivated as much by curiosity about me as anything else.

The interviews focused on the GPs' experience of practising ethics in their work. I asked them to practice. It uses qualitative research methods to analyse the ways in which a group of general 
Table 1 Characteristics of the general practitioners who participated in this study ${ }^{13}$

\begin{tabular}{llllll}
\hline & Age (years) & Sex & Location of work & Type of practice & Employment status \\
\hline Dr Alderson & 50 & Male & Large rural town & Large private group practice & Partner \\
Dr Bright & 63 & Male & Suburban city & Locum & Employed \\
Dr Dunt & 52 & Male & Small rural town & Solo private practice & Partner \\
Dr Elwin & 32 & Male & Suburban & Locum & Employed \\
Dr Johnson & 36 & Male & Outer suburban & 3 person private practice & Associate with a view \\
Dr Kingsford & 57 & Male & Small rural town & 3 person private practice & Partner \\
Dr Little & 48 & Male & Outer suburban & Government funded community health service & Employed \\
Dr Masters & 42 & Female & Suburban & Government funded community health service & Employed \\
Dr Newton & 44 & Female & Inner suburban & 2 person private practice & Partner \\
Dr Owen & 35 & Male & Rural town & 4 person private practice & Partner \\
Dr Silverman & 32 & Male & Rural industrial town & 5 person private practice & Partner \\
Dr Sing & 45 & Male & Suburban & Very large private practice & Employed \\
Dr Stamos & 30 & Male & Outer suburban & Large group private practice & Partner \\
Dr Williams & 34 & Female & Small rural town & 4 person private practice & Employed \\
Dr Winters & 33 & Male & Rural industrial & 3 person private practice & Partner \\
\hline
\end{tabular}

recall one or two ethical dilemmas they had encountered in their work as GPs and to talk about who was involved, in what ways, when and where things happened, and how it all turned out. They reflected on why they responded as they did, why the situation was a problem for them, and why they considered it to be an ethical problem. ${ }^{19}$ We also discussed the influences on the GPs' moral decision making, focusing on beliefs and values already identified in the interviews (for example, honesty), what those values meant for the GPs, and how they thought they had come to hold them.

The GPs described a wide range of moral problems. The issues they chose to discuss-relationships with colleagues, sickness certificates, workers' compensation, paternalism, euthanasia, abortion, making mistakes, confidentiality, domestic violence, treating family and friends, concealing information from a patient, chronic drug abuse, patients changing doctors-were broadly similar to those reported elsewhere as typical of ethical dilemmas in general practice. $^{18}{ }^{20-22}$

The GPs also articulated a variety of reasoning strategies. Their moral deliberation bore some of the characteristics of principlist, casuist, and virtuist reasoning, although it did not always share the rigour, logic, and coherence those approaches display in the scholarly literature. In this paper I wish to focus on the relationship between the GPs' talk about "being a good GP" and virtuist approaches to ethical analysis. The ways in which the GPs defined their moral problems has been reported elsewhere, ${ }^{18}$ as has the similarities between their moral reasoning and casuistic forms of ethical analysis. ${ }^{23}$

The GPs' virtuist approach to moral deliberation often remained hidden away in the background for much of each interview, nudging its way to the surface in a throwaway line or towards the end of an interview. For example, it was there when the GPs described the difference between general practice and specialist medicine, or when they talked about the "GP's style" or being "in general practice". It was apparent in comments like the following:

62. ${ }^{24}$ Dr Kingsford ${ }^{13}$ : I think as you get older you tend to ( ${ }^{\prime}$ ve had over 30 years in general practice) you tend to get to know how to handle these situations, and I think this just comes with experience, you know it's the science and art of medicine, and it's - you only pick up the art of medicine with experience ...

70. I think every doctor has their own style of practice. I've given a lot of thought to this over the years, and I think you're influenced by your peers and your teachers, and you develop a style of general practice. And the way you treat every person is different. For instance, a lot of teenagers, boys come in-sprained ankle-everything's black and white. Whereas other people will come in with a physical symptom, and then you sense that there's something more to it than that, and you have to talk to them for longer, and do more digging to find out what the real problem is. And this comes, it's just every GP's style, I think. You get to know people very well over a number of years and you can sense when they need a different sort of approach ...

These comments about developing a "style of general practice" do not relate in a straightforward manner to the analysis and resolution of specific moral dilemmas. Nonetheless, they reveal that, for this GP, at least part of the moral life concerns being, rather than doing, and instinctive, rather than rationalist, responses. Such responses are honed over long periods of time and learned and practised within a professional and social community.

In this paper, I wish to explore the characteristics of this "style of general practice" by addressing two questions. First, what defined general practice and the general practitioner for these GPs? And, second, what were the characteristics of a good GP?

\section{ACCESSIBILITY, COMPREHENSIVENESS, AND CONTINUITY AS IDEALS FOR GENERAL PRACTICE}

For the GPs in this study, general practice was characterised by three things:

\section{- Accessibility \\ - Comprehensiveness \\ - Continuity}

Furthermore, for GPs to be "good" GPs, they needed to explicate these three features in their daily practice in ways which took them above and beyond what was expected of other medical professionals. I will explore each of these concepts in turn.

First, the GPs in this study believed the general practitioner should be accessible. Accessibility is often interpreted as availability, usually in the context of being within reach via telephone or in the surgery. For the GPs in this study, accessibility meant more than this. It meant being contactable at a time and place that suited the patient. Dr Newton, a female GP working in an inner urban area, explored issues related to accessibility in her interview when she described how she went out of her way to visit older patients at home. Despite feeling uneasy about what her 
patients were asking of her, she clearly assumed GPs needed to be available to their patients, even if not always to the extent of her involvement.

\section{Dr Newton: I felt I looked after them [these patients who were elderly], to the best of my ability, in fact extremely well. And at times I'd put myself out a lot-not just a little bit-but a lot, on individual instances, and that had always been appreciated, or seemed to have been appreciated. And yes, I'll give you some beautiful examples. Some of these home visits I did when I went to pick the gentleman who had fallen often onto his wife, and couldn't move, I went because nobody else would go, and the family wouldn't go. The family said, no, get the doctor. And when I got there all I actually had to do was get him back on his feet, and make sure that they were all right. And that would happen, at virtually any hour of the day or night. They would ring, but I went. Well, I always went myself, and I never sent a locum ... That's going beyond the call of duty, on the whole.}

Secondly, the GPs believed good general practice was defined by its comprehensiveness. In the professional literature, comprehensive care often relates to the fact that GPs are generalists: they deal with all people and all problems presented to them. ${ }^{25}$ For the GPs in this study, comprehensiveness meant more. It included the notion that good medical care must go beyond physical and technical concerns to the social and emotional world of the patient. Dr Kingsford made this clear in his comments about the differences between specialists and general practitioners:

72. Dr Kingsford: specialists are a different type of doctor to a GP. I think specialists know a lot about a certain case. They can be very very bright in one or two areas, but quite often they have no bedside manner at all ... I mean, there's some very good specialists that are very goodlike psychiatrists, - that they can talk to people very well, but so many of them are just technicians, purely technicians and very very good technicians, but very poor doctors. I've found this many many times.

Dr Kingsford believed that the good GP accepted patients brought more to the consultation than just a physiological or pathological problem. Patients came with an array of experiences the GP needed to incorporate into the care he or she provided. Dr Owen thought his commitment to the "whole situation" was significant in the way GPs dealt with situations.

45. Dr Owen: There can never be black and white about one situation. I guess it's the, you really have to look at the whole picture. That's what we can certainly find in general practice is knowing the family, knowing the whole situation is much more useful than just knowing a picture, one frame of it, of the film.

During his interview he explored what this meant for an ethical problem he was facing-a young woman wanting to have her tubal ligation reversed. His conversation showed he had tried to build up a picture of this woman's "whole situation". He was as familiar with her social life as with her medical problems: he knew about her family, her relationships, and he had developed an understanding, over time, of what she wanted and needed in life.
49. Dr Owen: I think that she wants to have, I think that she wants to have another child, not for herself, but for her partner. That's the distinct impression that I get talking to her, that having a child would be part of binding their relationship together, making it more secure, and not any particular maternalistic reasons, reasons that she has. She is the sort of girl, I guess, who feels a desperate need to be loved and to have found a relationship which is satisfactory to her, something that's more than just a couple of weeks, or a night even, is something that's really good and she would hang on to that and probably try very to hard to hang on to that, because she's human, she needs the warmth and emotion that most people need. Whether those reasons are good reasons for her to have a baby is probably not for us to say yes or no to. And certainly, talking to her boyfriend, he's some sort of exbikie, ex-drug addict as well-I'm not sure how long he'll be around for as well because he's only been here for a short time. It's a hard one.

50. How many times have you seen her, talking about this particular episode?

51. Dr Owen: Seen her talking about having her tubes reversed? I've talked to her about four times about it, and she's quite insistent about it, about having it done, and I think, right she says she's cut down on her drinking. I've seen her do this before over the years, and it's just as likely to fall apart tomorrow if she has a big fight with her boyfriend, or if one of her old boyfriends turns up again and starts fighting. Two of her boyfriends had a big fight once before and they burnt half the house down in their fight. So they're pretty violent people sometimes.

Dr Owen's understanding of this woman's situation was not something that he had developed through one or two consultations. It was an awareness that had matured as he had come to know her well "over the years".

Dr Owen's desire to interpret and respond to the situation of the "whole person" also displays his commitment to the provision of the third ideal identified in this study-continuity of care. Many writers regard continuity of care as the cornerstone of general practice, even though there is not always clarity about what continuity means. Haggerty et al suggest that continuity seems to have three meanings in the literature. $^{26}$ The first two, informational and management continuity, relate to the creation and maintenance of shared systems for collecting information about and treating patients over time. Continuity, on these definitions, can refer to practices, just as much as individuals. The third meaning, "relational continuity", focuses on the ongoing relationship between GP and patient. Continuity, on this interpretation, develops over time as doctor and patient learn to know and trust each other and as the patient comes to identify one doctor as "his doctor". ${ }^{27} 28$

In principle the relational, informational, and management interpretations of continuity go hand in hand, because doctors who have ongoing information about and shared management plans for patients tend also to develop long term personal relationships. However, one can adopt informational and management continuity without buying in to relational continuity. Clearly, the relational interpretation demands considerably more of the individual GP in terms of personal involvement and time. Again, it was to the more demanding version of continuity that the GPs in this study turned when they were describing the "good GP". Dr Silverman, for example, believed continuity involved building relationships. 
64. Dr Silverman: Without a good trusting doctor-patient relationship you're not going to be able to achieve other things later.

65. Like what?

66. Dr Silverman: Like persuade people to go for other tests or investigations where you're not really certain of what's going on but the diagnosis is in doubt, that it may be something serious, but you want them to trust you, to go through it to make sure. If they say, "Well, if you're not really sure", or, "Doesn't seem that right, then why should I do it?" But if they trust you, they do it anyway. I know that sounds odd. Trust is very important for the long term management of patients. It is not in interim care, that in general practice it is continuity of care over a long period of time, and that means you've got to build up a relationship ...

Dr Little's view of continuity similarly emphasised the relationship the GP developed with both individuals and community over time.

96. Dr Little: Working in [a country town] for 12 years, to get to know a whole community from that point of view and to see a whole community move on a decade-in their ageing patterns, their growing-up patterns, their maturing patterns and marriage patterns. It's useful to slowly come to the realisation that change for people is a process rather than an event. You can't fix most of the problems of life in one go. It's not going to be one event of fixing things. It's a pattern of change that they might or might not want to commit themselves to. And just to sit back and take a longer-term view of what's going on in each person in each situation rather than trying to be the big hero that fixes it in one go.

A brief summary seems appropriate at this point. For the GPs in this study, three features of general practice made it distinct: accessibility, comprehensiveness, and continuity. Furthermore, "good" general practice meant incorporating these features into practice in ways which went beyond what ordinary medical practice required. In a sense, the GPs configured these three features as ideals to which they could (and did) aspire.

The GPs' ways of talking about these ideals had at least five of the features we often ascribe to virtuist approaches to ethical deliberation. First, as noted above, the image of good general practice and the virtues of general practice these GPs described were as much about being a certain kind of GP as they were about doing things in general practice. Because they were about being a good GP, the image and the virtues associated with it covered all aspects of the GPs' work, not just the morally problematic ones. Secondly, the virtues these GPs articulated were not intrinsic values. Rather, to use Pellegrino's words, they were traits "oriented to ends and purposes". ${ }^{29}$ The GPs seemed to value particular ideals because those ideals enhanced their capacity to "get things done" for their patients and, at the same time, allowed the GPs to create satisfying and meaningful lives for themselves. Thirdly, becoming a good GP was not something that happened overnight. It was a learnt way of responding to situations, grounded in one's life experiences. Fourthly, in the GPs' talk about the virtues in general practice there was an emphasis on practical wisdom and discernment. Good GPs were sensitive to context; they knew how to interpret situations and to moderate their responses accordingly. Dr Kingsford showed this particularly well in his comments about the contextual nature of honesty.
44. Dr Kingsford: I think you've always got to be honest, but there are ways of doing it. I wouldn't-I think you've also got to take into account their feelings, for instance. I think there are ways and means of being honest. If they come in and they ask you straight out, "Have I got cancer?" - I would always say, yes, if that was the case. But then I could also say it in such a way that-I don't think I would say, "Look, you're going to die", and be morbid about it, or something like that. I think you can be-the ways and means of breaking it to them gently, and let them form their own conclusions. I think this just comes with experience really, that you can treat people and say things to them, and be honest, but, by the same token, not take away all hope, as if they're going to go away and commit suicide or anything like that. You've always got to be honest, but then there is just a way of being honest, I think, a way of telling people things ...

Finally, good general practice, as these GPs described it, revolved around establishing and maintaining good relationships with patients. A good doctor develops a certain way of being a doctor that includes sensitivity to people's needs and "an ease with human relatedness". ${ }^{30}$

These five aspects of the GPs' descriptions of good general practice suggest that their way of talking and reasoning is similar to virtuist approaches to moral reasoning. Just as the approach shares some characteristics with virtue theory, so it also faced at least one of the difficulties. Critics of virtue theory have argued that there is a circularity about defining the virtues, when the definition is made contingent on agreement about the goods of medicine. This criticism seems particularly significant here. How did the GPs come to define good general practice in this way, other than by assuming that their versions of accessibility, comprehensiveness, and continuity are ideals for general practice? And what defines those ideals? In the final section of this paper I take up the issue of the source of these ideals by focusing on the social and organisational context in which good general practice was defined for these GPs.

\section{IDEALS IN SOCIAL CONTEXT: THE GOOD GP AS RURAL DOCTOR}

The GPs in this study had not just invented their ideals for general practice. On the contrary, their definition resembled to a considerable degree the professional definition of general practice offered by the RACGP ${ }^{31}{ }^{32}$ :

General practice is part of the Australian health care system and operates predominantly through private medical practices, which provide universal unreferred access to whole person medical care for individuals, families and communities. General practice care means comprehensive, coordinated and continuing medical care drawing on biomedical, psychological, social and environmental understandings of health.

A general practitioner is a registered medical practitioner who is qualified and competent for general practice in Australia. A general practitioner:

Has the skills and experience to provide whole person, comprehensive, coordinated and continuing medical care; and Maintains professional competence for general practice.

For these GPs, good GPs were, at least in part, GPs who exemplified the RACGP definition of general practice. But there is more to it than this, for the GPs who spoke most convincingly about the good GP also shared a commitment to 
community based general practice, particularly as it is practised by rural GPs.

I arrived at this conclusion by analysing the GPs' notions about good general practice in terms of their degree of commitment to rural general practice. I divided the GPs in two groups-a group of seven "rural" GPs and a group of six "urban" GPs. Two GPs whose interviews could not be analysed in detail were excluded from this part of the analysis. The "rural" GPs shared a history of work experience in and/or commitment to rural general practice. Five of them were working in rural South Australia at the time I interviewed them. In addition, Dr Elwin was about to move to the country, to begin a career in rural practice, and Dr Little, at that time working in an urban casualty service, drew on his rural experience during much of his interview.

When the GPs were grouped according to "rural" or "urban" orientation (table 2), it became apparent that the rural GPs were largely responsible for the account of the ideals of general practice that I have given above. Table 2 shows how significant these ideals were for each GP. The number of ticks indicates my assessment of how important the ideals were for each GP's discussion of ethical problems in their work. Only one urban GP, Dr Newton, mentioned these ideals at all. Apart from her contribution, discussion of these three features of good general practice care was restricted to the rural GPs, a number of whom talked about it in depth and detail, and with considerable passion.

What was it about the rural general practice experience of these GPs that created an environment for the articulation of these ideals? One plausible answer is the rural GPs in this study were able to articulate these features of care as ideals because the ways they defined those features resonated with the social and organisational context of their work as rural general practitioners. The urban GPs, however, practised in a different context, one that could not necessarily easily incorporate these ideals. The urban GPs became silent on the matter of virtue in general practice when their practice reality conflicted with professional conceptions of good practice.

This answer makes sense when we recall each of the ideals the GPs identified. First, continuity of care, in all its senses, is easier to provide in rural areas. As noted above, in Australia, patients have free choice of GP and may choose to see more than one GP in more than one practice if it suits them. However, patients in many rural areas have little, if any, choice of doctor or practice. ${ }^{33-35}$ There may be only one GP based in the town. Alternatively, in towns with three or fewer

Table 2 Ideals for general practice for "rural" and "urban" general practitioners (GPs)

\begin{tabular}{ll}
\hline GP* & $\begin{array}{c}\text { Accessibility, Comprehensive Care, } \\
\text { Continuity }\end{array}$ \\
\hline "Rural" GPs & \\
Dr Dunt & $\checkmark \checkmark$ \\
Dr Elwin & $\checkmark \checkmark \checkmark$ \\
Dr Kingsford & $\checkmark \checkmark \checkmark$ \\
Dr Little & $\checkmark \checkmark$ \\
Dr Owen & $\checkmark \checkmark \checkmark$ \\
Dr Silverman & $\checkmark \checkmark$ \\
Dr Winters & \\
"Urban" GPs & \\
Dr Bright & \\
Dr Johnson & \\
Dr Masters & \\
Dr Newton & $\checkmark$ \\
Dr Sing & \\
Dr Stamos & \\
\hline *This table excludes two doctors whose interviews could not \\
be analysed in detail.
\end{tabular}

GPs, the GPs generally work out of one group practice. Rural patients therefore have regular contact with the local GP out of geographic necessity, rather than by choice.

In addition, the relative isolation of rural towns in Australia provides opportunities for GPs to develop and maintain social relationships with patients. Rural GPs meet their patients at social functions, on local committees, while doing the shopping, at church and when taking children to school. Few GPs in urban practice have this out-of-hours contact with their patients, so there are fewer opportunities for them to develop relationships in this way.

In a similar way, rural GPs provide a more comprehensive service than their urban counterparts, in part because there are fewer alternatives available to their patients. Rural doctors provide a wider variety of services, including services which in urban areas are routinely handled by specialists or by other health professionals. The lack of mental health and welfare services in many rural areas is particularly important in this regard. Because the boundary between public and private lives are blurred in rural areas, doctors are better placed to make connections between the physical problems their patients bring to the surgery and their social and psychological contexts.

The third aspect of holistic care identified by the GPsaccessibility - appears, at first glance, to be more difficult to provide in rural areas, simply because urban GPs are usually geographically closer to their patients. Nevertheless, geographical proximity does not ensure that the GP is accessible. Out-of-hours care is a good example. In urban areas in Australia, many GPs use a deputising service for out-of-hours care or they arrange with colleagues in the practices around them to share out-of-hours care. In addition, there are large clinics operating a general practice service 24 hours per day, and some patients use these in preference to the deputising services. These arrangements ensure urban patients have relatively speedy access to general practice services outside normal practice hours. However, having access to $a$ GP is not the same as having access to your GP. For the GPs in this study, accessibility was a virtue when the GP provided it for his or her patients. Being accessible to one's own patients is, in some ways, not a virtue in rural practice: it is a necessity, for if the GP (or his or her partner) is not available, there is no care available to that patient at all. The lack of alternative services in rural areas forces GPs to be accessible, whether they wish to or not.

The virtues the rural GPs in this study articulated presented an idealistic image of the good GP as a family doctor and respected figure in the community who provided continuous care to communities they knew and in which they was known. Dr Kingsford described this close relationship between doctor and community beautifully.

121. Dr Kingsford: I like the country medicine and you get to know the people here. I mean, they're all your friends, everything, I mean you're in the local Lions Club. You get involved with people on the advisory board, doctor for the council area, and all the people, your friends. I don't think they'd let you leave. You just know them so well ...

While this account was idealised, it was also an image with which the rural GPs could identify. They spoke loudly and clearly about these ideals for general practice because they had experienced it in their own work. In rural general practice this image of the good GP could be a reality.

In contrast, the urban GPs were less likely to have had work experiences that could readily be squared with this idealised version of general practice. Accordingly, the urban GPs were less able to provide the accessibility, comprehensiveness, and 
continuity that were upheld as ideals for general practice. It is important here again to note that Dr Newton was the only urban GP to mention these ideals. Her circumstances were unusual: she had taken over her father's practice in a well established area with an ageing population and worked there for many years. Perhaps she was able to identify a "community" in the little section of suburbia in which she worked.

These findings are hardly new. Jon Berger and Jean Mohr's A Fortunate Man ${ }^{36}$ and W Eugene Smith's Country Doctor ${ }^{37}$ both offered accounts of the relationship between GPs and their communities that played on the notion of the good doctor as a cornerstone of community life. The symbiotic relationship between doctor and community exemplified there is mirrored in the account offered in this paper.

What is surprising is that such images still have currency 40 years later. Berger and Mohr and Smith wrote at a time when general practice was essentially the province of local community practitioners. Solo practitioners were the norm, the doctor provided a one-stop-shop for all health related services, and many social services as well, and GPs were respected and valued members of their communities. Today, general practice in this vein is much less common, to the point where many commentators believe it is disappearing altogether. Yet, the GPs in this study continued to look backwards for ideals of good general practice to a model of general practice current almost a generation ago.

What are the implications of these findings? One needs to be cautious about inferring too much from this small and exploratory study. Nonetheless, my findings do raise questions about the fit between ideals for and the reality of general practice in the twenty first century. Policy changes in both Australia and the UK are likely to lead to a decrease in personal continuity of care. How might one be a good GP in this environment? Is it possible to aspire to ideals of continuous, comprehensive, and accessible care when one is a member of a large team of doctors, supported by an array of other health professionals? And, can one translate these ideals into settings in which continuity is just not possible, for example with transitory populations or in locum work? The changing nature of general practice suggests that we may need to rethink both its definition and its ideals, if these concepts are to mean anything in the future.

\section{CONCLUSION}

For the predominantly rural GPs in this study who were able to articulate it, the good GP was a doctor who practised in a certain way, providing accessible, comprehensive, and continuing care to patients. The way in which the GPs used these ideals in their moral deliberation resembled virtue theory in style and, therefore, gave the GPs access to the strengths of virtue theory as a method for bioethics. It also exposed their moral deliberation to one of the difficulties with virtue theory: its tendency to define the virtues in terms of goods that are taken for granted. In the light of this criticism, the differences between rural and urban GPs I have discussed are not surprising. Virtue theory does not really address how values, virtues, and goods come to have the meanings they do. It therefore puts to one side considerations of the way in which social, organisation, and political factors shape our definitions of the good. In this study, it became apparent that it was the social and organisational context of the rural GPs' work which allowed them to adopt a set of ideals for general practice the urban GPs were unable to articulate.

\section{ACKNOWLEDGEMENTS}

The author acknowledges the support of Dr Neville Hicks and the helpful comments of the reviewers.
Later drafts of this paper were written while the author was a Visiting Research Fellow at the Centre for Ethics in Medicine, University of Bristol. The paper was first presented at a seminar at the Centre for Primary Care and Social Medicine, Imperial College of Science, Technology and Medicine, London.

\section{REFERENCES}

1 Oakley J. Varieties of virtue ethics. In: Freeman M, eds. Ethics and Medical Decision-making. Oxford: Blackwell, 1996:315-39.

2 Statman D, ed. Virtue Ethics: A Critical Reader. Edinburgh: Edinburgh University Press, 1997.

3 Pellegrino ED, Thomasma DC. The Virtues in Medical Practice. New York: Oxford University Press, 1993.

4 Drane JF. Character and the moral life. In: Dubose ER, Hamel RP, O'Connell U, eds. A Matter of Principles? Ferment in US Bioethics. Pennsylvania: Trinity Press International, 1994:283-309.

5 See reference 3: Chapter 2.

6 Pellegrino, ed. Toward a virtue-based normative ethics for the health professions. Kennedy Inst Ethics J 1995:5:253-60.

7 May W. The virtues in a professional setting. In: Fulford KWM, Gillett GR, Soskice JM, eds. Medicine and Moral Reasoning. Cambridge: Cambridge University Press, 1994:75-90.

8 Whitbeck C. The trouble with dilemmas: rethinking applied ethics. Prof Ethics 1992;1:119-42.

9 Swift TL, Ashcroft RE, Tadd W, et al. Living well through chronic illness: the relevance of virtue theory to patients with chronic osteoarthritis. Arthritis Rheum 2002;47:474-8.

10 Toon P. What is Good General Practice? A Philosophical Study of the Concept of High Quality Medical Care. Occasional Paper 65. London: Royal College of General Practitioners, 1994.

11 Toon P. The sovereignty of virtue. Br J Gen Pract 2002;52:694-5.

12 The biographical details have been altered slightly in a few cases to protect the GPs' anonymity.

13 All participants have been given pseudonyms.

14 Braunack-Mayer AJ, Hicks N. Needs Assessment for the Adelaide Central and Eastern Division of General Practice. Adelaide: Department of Community Medicine, 1994.

15 Braunack-Mayer AJ, Marley J. Yorke Peninsula Needs Assessment, for the Yorke Peninsula Division of General Practice. Adelaide: Department of Community Medicine, 1995

16 Hicks N, Reynolds C, Braunack-Mayer A. Ethical Issues Associated with Sources of Funding for Divisions of General Practice. Canberra: Department of Human Services and Health, 1996.

17 Wittwer T, Braunack-Mayer AJ, Moss JR, et al. Upskilling in Counselling for GPs, Final Report for the Adelaide Hills Division of General Practice. Adelaide: Department of Public Health, 1998.

18 Beilby J, Braunack-Mayer AJ, Moss JR, et al. Evaluation of an Obstetric Shared Care Program. Adelaide: Department of General Practice, 1997.

19 Braunack-Mayer AJ. What makes a problem an ethical problem? An empirical perspective on the nature of ethical problems in general practice. J Med Ethics 2001;27:98-103.

20 Rogers WA. A systematic review of empirical research into ethics in general practice. Br J Gen Pract 1997:47:733-7.

21 Christie RJ, Freer C, Hoffmaster CB, et al. Ethical decision making by British general practitioners. J R Coll Br Gen Pract 1989;39:448-51.

22 Sugarman J. 20 Common Problems: Ethics in Primary Care. New York: McGraw-Hill Professional, 2000.

23 Braunack-Mayer AJ. Casuistry as bioethical method: an empirical perspective. Soc Sci Med 2001;53:71-81.

24 Numbers refer to paragraph marks in the interview transcripts.

25 Strasser R. General practice - what is it? Med J Aust 1991;155:533.

26 Haggerty JL, Reid RJ, Freeman GK, Starfield BH, Adair CE, McKendry R. Continuity of care: a multidisciplinary review. BMJ 2003;327:1219-21.

27 Murtagh J. General Practice. Sydney: McGraw-Hill, 1994.

28 McWhinney I. A Textbook of Family Medicine. New York: Oxford University Press, 1989.

29 See reference 6:256.

30 See reference $4: 287$

31 Royal Australian College of General Practitioners. Definition of General Practice and General Practitioner 2002. Available at www.racgp.org.au/ document. asp?id= 6234 (accessed 5 February 2003).

32 Royal Australian College of General Practitioners. Minutes of 26/27 July 1997 meeting of the RACGP Council. See Appendix 4 39/10 Council Minutes, 26/27 July, 1997.

33 Moorhead B. Some differences between Australian country and city general practice. Aust Fam Phys. 1990;19: 531, 533-5, 537

34 Fisher E. Rural practice: reward or punishment? Aust Fam Phys 1988;17:141-2.

35 Purtilo R, Sorrell J. The ethical dilemmas of a rural physician. Hastings Cent Rep 1986;16:24-8.

36 Berger J, Mohr J. A Fortunate Man: The Story of a Country Doctor. London: Penguin Press, 1967.

37 Eugene Smith W. Country Doctor. Life Magazine. 20 September 1948 Available at www.life.com/Life/essay/country doctor/ (accessed 24 November 2003). 